\title{
Bacterial Communities in Aquatic Sediment from Bukit Duabelas Raintforest and Oil Palm Plantation at Sumatra Indonesia
}

\author{
Marini Wijayanti ${ }^{1,4}$, Aris Tri Wahyudi ${ }^{1}$, Munti Yuhana ${ }^{2}$, Martin Engelhaupt ${ }^{3}$, Anja Meryandini ${ }^{*}$ \\ ${ }^{1}$ Department of Biology, Faculty of Mathematics and Natural Sciences, Bogor Agricultural University, Bogor, Indonesia \\ ${ }^{2}$ Department of Aquaculture, Faculty of Fisheries \& Marine Science, Bogor Agricultural University, Bogor, Indonesia \\ ${ }^{3}$ Göttingen Genomics Laboratory, George August University Göttingen, Germany \\ ${ }^{4}$ Department of Aquaculture, Faculty of Agriculture, Sriwijaya University, Ogan Ilir, Indonesia
}

ARTICLE INFO

Article history:

Received March 8, 2017

Received in revised form February 2, 2018

Accepted February 5, 2018

\section{KEYWORDS:}

aquatic sediment, bacterial communities,

rainforest,

oil palm plantation,

Sumatra-Indonesia

\begin{abstract}
The diversity of bacterial communities in aquatic sediment of rainforest and oil palm plantation at Sumatra was studied using pyrosequencing of 16S rRNA gene and common biodiversity indices. Phylogenetic approach was used for revealing the community shift of bacterial phyla and genera in both areas. Ecological approach used soil pH, total Carbon (TC), total Nitrogen (TN), available Phosphorus (AP) measurement and bacterial diversity with Shanon and Simpson indices, and bacterial richness with Chao1-ACE indices and OTUs. Bacterial diversity and richness in aquatic sediment of forest area was higher than that ones in oil palm plantation area, although their $\mathrm{pH}, \mathrm{TC}$, and $\mathrm{TN}$ in both areas were not different significantly. The majority of sequences related to Proteobacteria $(34.85 \%)$, Acidobacteria (32.67\%), Nitrospirae (6.86\%), Chloroflexi $(4.31 \%)$, and Actinobacteria (4.02\%) were from forest; whereas those related to Acidobacteria (46.10\%), Proteobacteria (25.86\%), Nitrospirae (9.20\%), Chloroflexi $(4.99 \%)$, and Actinobacteria $(\mathbf{2 . 3 4 \%})$ invented from oil palm plantation. The genera of Alphaproteobacteria and Betaproteobacteria dominated in genera phylotype of bacterial 16S rRNA phylogenetic revealed both aquatic sediment of forest and oil palm plantation. The most genera in the phylogenetic tree from aquatic sediment of both areas was Burkholderia. The bacterial community shift in aquatic sediment of forest transformation indicated higher bacterial diversity index, richness index, some of phyla and genera in aquatic sediment from forest than from oil palm plantation.
\end{abstract}

\section{Introduction}

Oil palm (Elaeis guineensis) is one of the most rapidly expanding crops in the tropics. Most of this increase has taken place in Southeast Asia. Malaysia and Indonesia account for almost $85 \%$ of the 46.5 million tons of crude oil palm produced in the world, Indonesia being the top producer since 2007. Oil palm plantation development in Southeast Asia has been claimed as triggering deforestation and loss of biodiversity, peat land degradation, and high greenhouse gas (GHG) emissions (Comte et al. 2012). One reason was the conversion of the huge forest zone to oil palm plantations over the river basin which caused modifications in the surface soil layer and vegetation canopy. Land-use variation plays a vital role in local water cycle changes, especially for the water movement within the soil layer (Tan et al. 2012).The

\footnotetext{
* Corresponding Author.

E-mail Address: ameryandini@ipb.ac.id
}

use of agrochemicals, such as fertilizers and pesticides, might represent a potential risk for the sustainability of aquatic ecosystem and hydrological functions when agricultural practices are not optimized. In particular, oil palm growers usually apply large amounts of commercial fertilizer and thus are among the largest consumers of mineral fertilizers in Southeast Asia. Hydrological processes within oil palm plantations are still not fully understood, and few studies have examined the impacts of agricultural practices on terrestrial hydrological functions and water quality in nearby aquatic ecosystems (Ah Tung et al. 2009; Comte et al. 2012).

Sediment microbial communities are responsible for a majority of the metabolic activity in river and stream ecosystems. Understanding the dynamics in community structure and function across freshwater environments will help us to predict how these ecosystems will change in response to human landuse practices (Gibbons et al. 2014). High fertilizer input is necessary to sustain high yields in oil palm agroecosystems, but it may endanger neighboring 
aquatic ecosystems when excess nutrients are transported to waterways. The low nutrient concentrations recorded in streams throughout the landscape indicated that the mature oil palm plantations did not contribute to eutrophication of aquatic ecosystems. Soil type controlled dissolved inorganic $\mathrm{N}$ and total $\mathrm{P}$ fluxes, with greater losses of $\mathrm{N}$ and $\mathrm{P}$ from loamy-sand uplands than loamy lowlands (Comte et al. 2015). The change of water nutrient cause change of microbial community in the water which is dominated in water sediment habitat.

Deforestation made decreasing in biodiversity, include in bacterial diversity. This study described the impact of forest transformation to oil palm plantation in bacterial community shift based on ecological and phylogenetically approach. The case study in small river at the Bukit Duabelas rain forest and the oil palm transformation nearby the forest will describe this impact.

\section{Materials and Methods}

\subsection{Samples Collection and Preparation}

Samples used for this research were derived from sediment in fresh water near these sites. Soils in the Bukit Duabelas area are represented by clay Acrisols and in the oil palm plantation are represented by modified Acrisols (Guillaume et al. 2015). The forest is located in Bukit Duabelas National Park, and the oil palm plantation is near the forest in Sarolangun District, Jambi Province, Indonesia. SBF1, SBF3, and SBF4 were notation used on the aquatic sediment sample from forest area, and SBO2, SBO3, and SBO4 for aquatic sediment of oil palm plantation area. Both sediments were under interstitial pore water and surface water. In each of these six sub areas, small cores were collected in five replicates and triplicates of each core (approximately 10 grams) from surface sediment (approximately $5-20 \mathrm{~cm}$ from the water surface, in depth about $5 \mathrm{~cm}$ from sediment surface), using a small shovel and tube (approximately 2 inches in diameter). The samples have been maintained at $\pm 30^{\circ} \mathrm{C}$. Samples from the same area were combined and mixed completely to produce one homogeneous sample. This study was done at Laboratory of Microbiology, Faculty of Mathematic and Natural Science, Bogor Agricultural University and Göttingen Genomics Laboratory, George August University of Göttingen, Germany.

Acidity of soil and sediment was in situ measured with a $\mathrm{pH}$ meter. All chemical parameters of soil (acidity, Carbon, Nitrogen, available Phosphorus) were determined according to ISRIC standards (Van Reeuwijk 2000) at the Soil Research Institute, Bogor, Indonesia. All samples were kept on ice up to arrival at the laboratory and then were stored at $4^{\circ} \mathrm{C}$. Samples from the same area were combined and mixed completely to produce one homogeneous sample. These samples are $\mathrm{SBF}$ (aquatic sediment from lowland forest), and SBO (aquatic sediment from oil palm plantation).

\subsection{DNA Extraction}

Total microbial community DNA was isolated from $10 \mathrm{~g}$ of soil or sediment per sample. For this purpose, the Mo Bio Power Soil DNA extraction kit (Mo Bio Laboratories, Carlsbad, CA) was used according to the instructions of the manufacturer. The Power Soil ${ }^{\circledR}$ DNA Isolation Kit from MO BIO Laboratories, Inc., was applied according to the manufacturer's instructions. The kit contained a special inhibitor removal solution for the removal of humic acids and other disturbing substances. A special solution was included which allows the removal of humic substances, respectively brown color from even the most difficult soil types (Ettenauer et al. 2012).

The concentration and quality of the DNA preparations were estimated by a NanoDrop spectrophotometer and by electrophoresis on $0.8 \%$ agarose gels. Measurements were assessed using a NanoDrop ${ }^{\circledR}$ ND-1000 spectrophotometer (peqLab Biotechnologie $\mathrm{GmbH}$, Linz, Austria). The analyses were performed according to the manufacturers' protocol and the extracted DNA of all triplicate sample amounts from the method was measured three times. Mean values were calculated for each sample amount. The purity of the extracted DNA was assessed by measuring the A260/A280 absorbance ratio which indicates the presence of impurities as protein, phenol, humic acids or other contaminants that strongly absorb at or near $280 \mathrm{~nm}$. They were used for the electrophoresis and for the PCR amplifications.

\subsection{Pyrosequencing Preparation and Analysis}

Bacterial 16S rRNA genes were amplified using the forward primer 343F (5'-TACG-GRAGGCAGCAG -3') and the reverse primer 909R (5'-CCGTCAATTCMTTTGAGT -3') (Liu et al. 2007; Wang et al. 2007). Products were confirmed by subjecting $2 \mu \mathrm{l}$ of each sample to electrophoresis on a $0.8 \%$ agarose gel. The PCRs were carried out in triplicate with $50 \mu \mathrm{l}$ of the reaction mixture comprising $10 \mu \mathrm{l}$ of 10 -fold Phusion buffer, $1 \mu \mathrm{l}$ of $10 \mathrm{mM}$ dNTPs, $1 \mu \mathrm{l}$ of each primer (1:10), 2-5 $\mu \mathrm{l}$ of diluted DNA sample, $0.5 \mu \mathrm{l}$ of Phusion HS DNA Polymerase $(2 \mathrm{U} / \mathrm{\mu l})$, and approximately $10 \mathrm{ng}$ of DNA template by using the programmable thermo cycler (MJ Research PTC-200 Peltier Thermal Cycler, MJ Research, Inc., Malham, USA). The amplification program consisted of an initial denaturation step at $98^{\circ} \mathrm{C}$ for $5 \mathrm{~min}$, followed by 25 cycles of denaturation at $98^{\circ} \mathrm{C}$ for $45 \mathrm{sec}$, annealing at $55-68^{\circ} \mathrm{C}$ for $45 \mathrm{sec}$, and elongation at $72^{\circ} \mathrm{C}$ for $30 \mathrm{sec}$, with a final extension step at $72^{\circ} \mathrm{C}$ for $5 \mathrm{~min}$. The replicate PCR products of the same soil treating group were assembled within a PCR tube. The PCR products were visualized on agarose gels $(0.8 \%$ in TAE buffer) containing ethidium bromide, and purified using a peqGOLD 
Gel Extraction Kit (PEQLAB Biotechnologie GmbH, Erlangen, Germany). In general, gel extraction was performed according to manufacturer's instruction. Quantification of the PCR products was performed by using the Quant-iT dsDNA BR assay kit and a Qubit fluorometer (Invitrogen $\mathrm{GmbH}$, Karlsruhe, Germany) as recommended by the manufacturer. The Goettingen Genomics Laboratory determined the sequences of the partial 16S rRNA genes by employing the Roche GSFLX 454 pyrosequencer (Roche, Mannheim, Germany) and using picotiter sequencing plates subdivided into 8 parts ( 1 part per sample). Amplicons were sequenced as recommended in the instructions of the manufacturer for amplicon sequencing (Will et al. 2010).

In the quality filtering, several filtering options can be set, if sequences that were too short (less than 250 base pair) or too long (more than 1000 base pairs), or have more than 8 bases of the same base in a row had been filtered out of the total dataset. The Quality filtering had also given the number of raw sequence from the initial sequence dataset after sequencing (in the first line of the table) and the number of sequences after quality filtering. With this sequence number the next steps of the analysis had been done. Furthermore, the table explained the minimal, maximal and the average sequence length for each of the samples. The next step for processing the sequence data was to cluster the sequences into Operational Taxonomic Units (OTUs). That means that all sequences in all of the samples had been compared to each other and if there is similarity between the sequences, they had been grouped into one OTU. The grouping was based on a sequence similarity of $99 \%$. So, if some sequences were at least $99 \%$ similar to each other than compared to other sequences in the dataset, they were grouped together. After grouping the sequences into OTUs, from each OTU one representative sequences had been picked. With this representative sequence from each OTU the taxonomic assignment had been made. This means that the representative sequences had been classified by their taxonomy. This taxonomic assignment made by using a database which include huge amount of already known $16 S$ rRNA sequences. The database used for the taxonomic assignment is the SILVA SSURef NR 111 database (http://www. arb-silva.de/) (Quast et al. 2012). After taxonomic assignment, the number of sequences in this particular OTU for each of the samples, and the respective taxonomic classification, we calculated rarefaction curves as well as the Shannon index based on OTU picker data, by employing the RDP pyrosequencing pipeline (Cole et al. 2009; Magurran and McGill 2011). ACE and Chao1 indices (Chao and Bunge 2002) were calculated using the RDP tools.

All the 16Sr RNA gene sequences were deposited in the NCBI Sequence Read Archive (SRA) under the Bioproject PRJNA288716. All the experimental research that is reported in the manuscript has been appropriate ethics committee. There was not experimental research neither on humans nor on animals.

\subsection{Phylogenetic Analysis}

The Ribosomal Database Project and the BLASTN 2.0.6 algorithm of GenBank were employed to search for close evolutionary relatives of the 16S rRNA gene sequences of bacterial isolates. Alignments were generated with ClustalW. The partial 16S rRNA genes were sequenced at two different sites, forward, and reverse, with an overlap between the sequences. Therefore, it was possible to align both sequences from the same isolate to get a longer fragment of the 16S rRNA region. Aligning the two sequences led to a consensus sequence. Furthermore, false base pairs could be edited and exchanged, or added, if there were missing base pairs. The consensus sequence was copied and compared with an NCBI database sequences from isolates and reference sequences from known strains, and sequences from the results of the NCBI search were aligned with the Aligner program from http://www.arb-silva.de/ (http://www.arb-silva. de/aligner/). The phylogenetic tree was constructed with the MEGA6 program by using Maximum Likelihood methods. Bootstrapping (Felsenstein 1985) was used to estimate the reliability of phylogenetic reconstructions with 1000 replicates.

\section{Results}

The compositions of sediment bacterial communities present in two different soil systems derived from a forest site (site SBF) and an oil palm plantation site (site SBO) were assessed and compared using pyrosequencing-based analysis of 16S rRNA gene sequences. They could be influenced by sediment chemical properties of samples from different land use types, the forest and oil palm plantation sites such as soil $\mathrm{pH}$, Total Carbon (TC), Total Nitrogen (TN), Available Phosphorus (AP), and $\mathrm{C} / \mathrm{N}$ ratio (Table 1 ). The $\mathrm{t}$-test of two analyzed soil area showed no significant differences in some sediment parameters ( $\mathrm{pH}, \mathrm{TC}, \mathrm{TN}$, and $\mathrm{C} / \mathrm{N}$ ratio), but significant differences in available phosphorus (AP) and $\mathrm{C} / \mathrm{N} / \mathrm{P}$ ratio. The available $P$ content of the sediment of site SBF $(0.281 \%)$ was higher than that of site SBO $(0.044 \%)$, the $\mathrm{C} / \mathrm{N} / \mathrm{P}$ ratio of site $\mathrm{SBO}(0.273)$ was higher than that of site SBF (0.049). Available phosphorus varied significantly between forest and nonforest sites, while soil $\mathrm{pH}$, total carbon, total nitrogen, and $\mathrm{C} / \mathrm{N}$ ratio did not vary significantly across the landscape.

Pyrosequencing analysis of environmental samples can obtain much more sequences and OTUs than conventional cloning and sequencing methods. The higher Shannon and OTUs indices of sediment bacteria in forest than in oil palm plantation (Figure 1), observed in this study demonstrated the usefulness of pyrosequencing analysis in revealing the bacterial diversity and richness from 
Table 1. Mean values ( \pm standard deviation) of parameters for sediment samples from the forest site (SBF) and the oil palm plantation site (SBO)

\begin{tabular}{ccccccc}
\hline Sample sites & $\mathrm{pH}\left(\mathrm{H}_{2} \mathrm{O}\right)$ & $\mathrm{pH}(\mathrm{KCl})$ & $\mathrm{TC}(\%)$ & $\mathrm{TN}(\%)$ & $\mathrm{AP}(\%)$ & $\mathrm{C} / \mathrm{N} \mathrm{ratio}$ \\
\hline SBF & $4.500 \pm 0.557$ & $3.900 \pm 0.361$ & $3.540 \pm 3,090$ & $0.233 \pm 0.150$ & $0.281 \pm 0.074$ & $13.700 \pm 3480$ \\
SBO & $4.800 \pm 0.100$ & $3.967 \pm 0.208$ & $1.725 \pm 0.205$ & $0.145 \pm 0.005$ & $0.044 \pm 0.005$ & $11.870 \pm 1.000$ \\
\hline
\end{tabular}

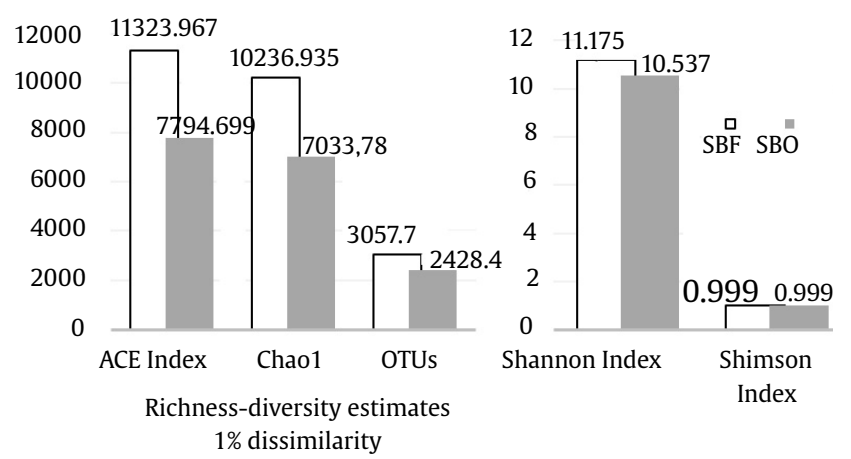

Figure 1. Bacterial richness indices of aggregates and whole sediment at a genetic distance of $1 \%$, expressed as the number of observed unique OTUs, ACE, Chao1, Shannon Index, and Simpson Index

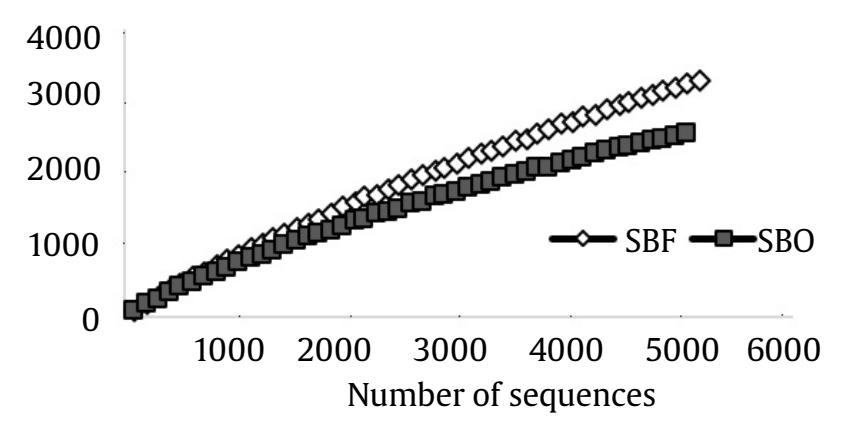

Figure 2. Rarefaction curves showing the observed number of operational taxonomic units (OTUs) at $1 \%$ dissimilarity for samples from sites SBF and SBO

the tropical low land rainforest as nature area and the oil palm plantation as deforestation area. Libraries of sites SBF and SBO were composed of 2968 and 2186 OTUs, respectively. Rarefaction curves were generated at $1 \%$ cutoff to make a comparison of species richness between the two soil groups (Figure 2).

Based on ACE and Chao1 indices of both bacterial richness from site SBF displayed relatively higher species richness than those from site SBO (Figure 1). When the genetic distances were 0.01 , the value of ACE, Chao1, and OTU for samples from site SBF was 11323, 10236, and 3057, whereas that for samples from site SBO was 7794,7033 , and 2428 respectively. Both the Shannon and Simpson diversity indices revealed similar trends, with higher values observed for samples from site SBF (11.175 and 0.999), when compared with those from site SBO (10.537 and 0.999) relatively, but they were not differences considerably. It was confirming the similarity bacterial richness and diversity in both sites.

The 5154 classifiable sequences were affiliated with 23 phyla across the entire data set. The major phylum groups were those with a relative abundance of $>2 \%$. Figure 3 shows the phylum compositions of the two soil groups. Site SBF was mainly composed of Proteobacteria (34.85\%), Acidobacteria (32.67\%), Nitrospirae (6.86\%), Chloroflexi (4.31\%), Actinobacteria (4.02\%), Spirochaetes (3.38\%), Chlorobi (3.36\%), and Bacteroidetes (3.23\%). Site SBO mostly comprised Acidobacteria (46.10\%), Proteobacteria (25.86\%), Nitrospirae (9.20\%), Chloroflexi (4.99\%), Spirochaetes (2.38\%), and Actinobacteria (2.34\%). Proteobacteria contributed to the majority of bacterial communities in forest sediment, even though Acidobacteria contributed to the majority of bacterial composition of oil palm plantation sediment. Five genera dominated in both two sites were included to Acidobacteria phylum. The dominant bacterial phyla from both of two areas were Acidobacteria.

The dissimilarities among the samples at the class level of taxonomic classifications were found in this study (Figure 4). Acidobacteria, Alphaproteobacteria, Deltaproteobacteria, Betaproteobacteria, and Nitrospira were the most dominant classes (>5.00\%) in site SBF, accounting for $31.22 \%, 10.65 \%, 10.55 \%, 9.59 \%$, and $6.86 \%$ of the total bacterial sequences, respectively. In site SBO, several classes were dominant $(>5.00 \%)$ such as Acidobacteria, Nitrospira, Deltaproteobacteria, Alphaproteobacteria, and Betaproteobacteria, accounting for $42.94 \%, 9.20 \%, 8.65 \%, 7.35 \%$, and $6.11 \%$ of the total bacterial sequences, respectively. The two areas sediment revealed obvious similarity in the abundances of the class Acidobacteria of the most dominant phylum, Acidobacteria, as like as in two areas soil.

Analyzing at the genus level showed an enrichment trend of beneficial bacterial groups in the soil. The relative abundance of any genus was $<0.5 \%$ in each sample, implying high bacterial diversity in the two sample groups. Among the top 50 predominant genera in the soils evaluated (Figure 4), the ten greater bacterial genera were common in the SBF sites: Acidobacteria DA052 uncultured bacterium (7.56\%), Acidobacteriales uncultured bacterium (7.42\%), Bryobacter (3.73\%), Spirochaeta (3.03\%), Gammaproteobacteria Sinobacteraceae uncultured (3.02\%), Acidobacteria DA023 uncultured bacterium (2.53\%), Chlorobi Ignavibacteriales BSV26 uncultured bacterium (2.46\%), Acidobacteria Candidatus Solibacter uncultured bacterium (2.42\%), and Nitrospirales 4-29 uncultured bacterium (2.13\%). Ten genera were dominant in the SBO sites: Acidobacteriales uncultured bacterium (11.67\%), Acidobacteria DA052 uncultured bacterium (10.39\%), Bryobacter (3.83\%), Acidobacteria DA023 uncultured bacterium (3.77\%), GammaproteobacteriaSinobacteraceaeuncultured(3.22\%), 


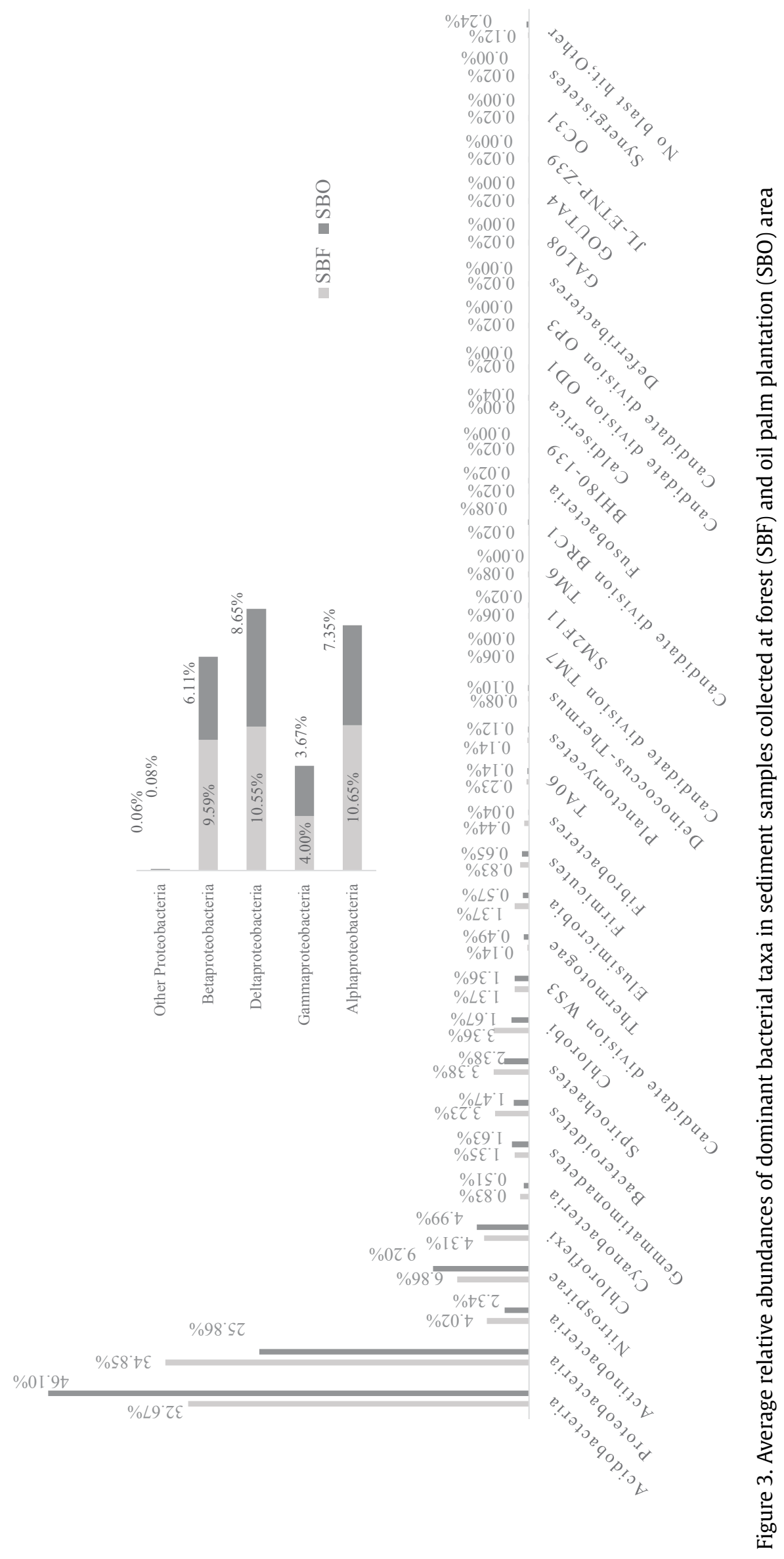




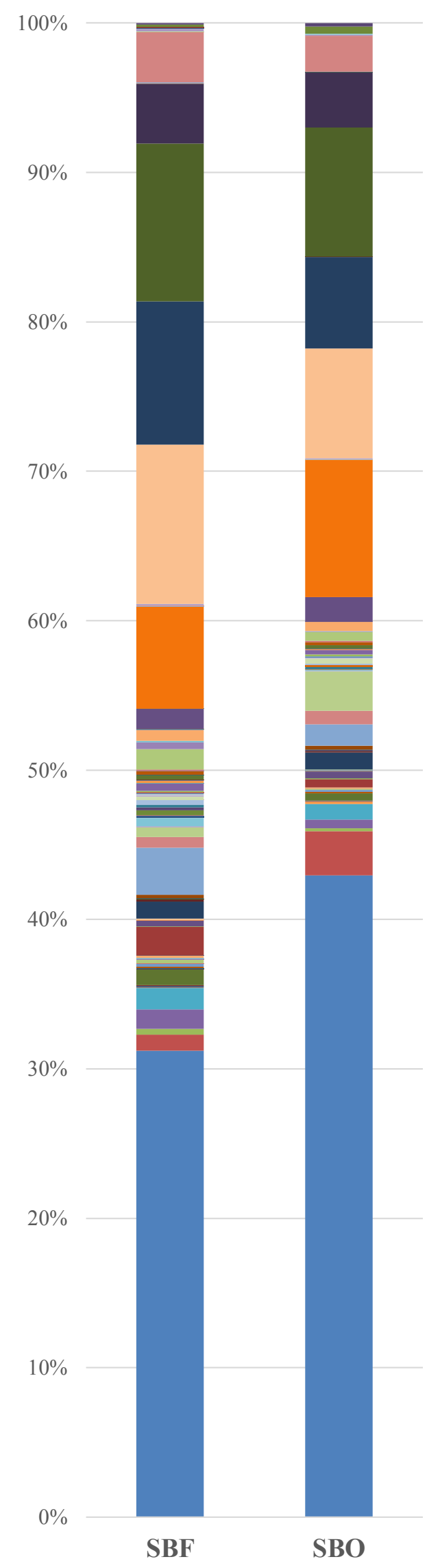

- No blast hit;Other;Other

- Thermotogae;Thermotogae

TM6; uncultured bacterium

- TA06; uncultured soil bacterium

- TA06; uncultured bacterium SHA-114

- TA06; uncultured bacterium

Synergistetes;Synergistia

Spirochaetes;Spirochaetes
- SM2F11;uncultured bacterium

- Proteobacteria;TA18

- Proteobacteria;TA18
- Proteobacteria;:SK259

- Proteobacteria;SK259

- Proteobacteria;Deltaproteobacteria

- Proteobacteria;Class Incertae Sedis

- Proteobacteria;Betaproteobacteria

Proteobacteria;Alphaproteobacteria

- Planctomycetes;Planctomycetacia

Planctomycetes;Pla4 lineage

Planctomycetes;Phycisphaer

- OC3!

OC31; uncultured bacterium

- Nitrospirae; Nitrospira

JL-ETNP-Z39; uncultured organism

- Gemmatimonadetes;Gemmatimonadete

GOUTA4; uncultured bacterium

- GAL08; uncultured bacterium

- Fusobacteria;Fusobacteria

Firmicutes;Clostridi

- Firmicutes;Bacilli

Fibrobacteres;Fibrobacteria

Elusimicrobia;Elusimicrobia

- Deinococcus-Thermus;Deinococc

- Deferribacteres;Deferribactere

- Cyanobacteria;WD272

- Cyanobacteria;SM1D11

- Cyanobacteria;SHA-109

- Cyanobacteria;MLE1-12

- Cyanobacteria;ML635J-21

- Cyanobacteria;Cyanobacteria

Cyanobacteria;Chloroplast

- Cyanobacteria;4C0d-2

- Chloroflexi;vadinBA26

- Chloroflexi;TK10

- Chloroflexi;Sh765B-AG-111

- Chloroflexi;SHA-26

Chloroflexi;SAR202 clade

- Chloroflexi;S085

- Chloroflexi;MSBL5

Chloroflexi;Ktedonobacteria

- Chloroflexi;KZNMV-5-B42

Chloroflexi;KD4-96

Chloroflexi,JG37-AG-4

- Chloroflexi;JG30-KF-CM66

- Chloroflexi;GIF9

- Chloroflexi;GIF3

- Chloroflexi;FW22

- Chloroflexi;FS117-23B-02

- Chloroflexi;Elev-1554

Chloroflexi;Dehalococcoidetes

- Chloroflexi;Chloroflexi

- Chloroflexi;Caldilineae

- Chloroflexi;Anaerolineae

- Chlorobi;Innavibacteria

- Chlorobi;Chlorobia

- Candidate division WS3; uncultured soil bacterium PRR-12

- Candidate division WS3; uncultured soil bacterium PBS-III-30

- Candidate division WS3; uncultured prokaryote

- Candidate division WS3; uncultured candidate division WS3 bacterium

- Candidate division WS3; uncultured bacterium

- Candidate division TM7; uncultured bacterium.

- Candidate division OP3; uncultured bacterium

- Candidate division OD1; uncultured bacterium

- Candidate division BRC1;uncultured soil bacterium PBS-III-18

- Candidate division BRC1; uncultured organism

Candidate division $\mathrm{BRCl}$; uncultured delta proteobacterium

- Candidate division BRC1; uncultured bacterium

- Caldiserica;Caldisericia

- Bacteroidetes; vadinHA17

- Bacteroidetes;WCHB1-32

- Bacteroidetes;Sphingobacteriia

- Bacteroidetes;SM1A07

- Bacteroidetes;SB-5

- Bacteroidetes; SB-

- Bacteroidetes;Flavobacteria

- Bacteroidetes;Cytophagia

- Bacteroidetes; Class Incertae Sedis

- Bacteroidetes;Bacteroidia

- Bacteroidetes;BSV13

- Bacteroidetes;BD2-2

- BHI80-139; uncultured bacterium

- Actinobacteria;Thermoleophilia

- Actinobacteria;OPB41

- Actinobacteria;MB-A2-108

- Actinobacteria:Coriobacterii

- Actinobacteria; Actinobacteria

- Actinobacteria;Acidimicrobiia

- Acidobacteria;RB25

- Acidobacteria;Holophagae

- Acidobacteria; Acidobacteria

Figure 4. 16S rRNA gene surveys revealed a clear distinction between the two bacterial class populations investigated. Comparison of the percentage of sequences (relative abundances) affiliated with different classes from sites SBF and SBO 
Nitrospirales 0319-6A21 uncultured bacterium(3.05\%), Acidobacteria Candidatus Solibacter uncultured bacterium (2.83\%), Chloroflexi Caldilineaceae uncultured (2.63\%), Nitrospirales 4-29 uncultured bacterium (2.40\%), and Acidobacteria Candidatus Koribacter (2.24\%). However, the compositions of the bacterial community and the distributions of the dominant 50 genera were different between samples from sites SBF and SBO. The respective abundance of the 50 most represented genera in the samples from the two sites were examined (Figure 5 ), there were seven genera in SBF and five genera in SBO sites which more abundance than others genera in both sites. Comparison of the overall distribution of the selected 12 dominant genera (more than $5 \%$ of total sequences) from 50 predominant genera within sites SBF and/or SBO (Figure 6) showed that Acidobacteria was the most dominant genera.

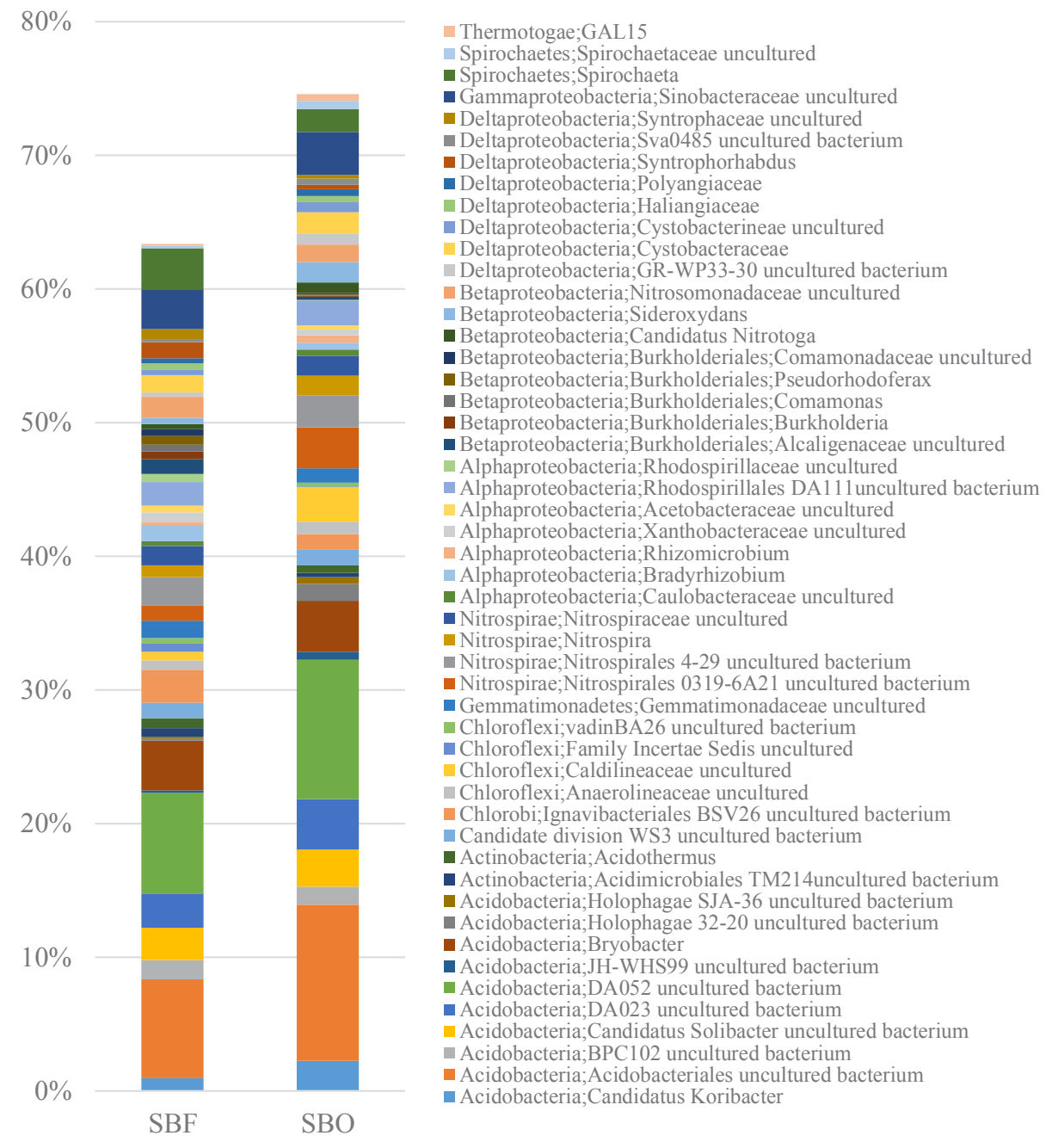

Figure 5. Comparison of the overall distribution of 50 predominant genera (more than $0.5 \%$ of total sequenes) within sites SBF and/or SBO

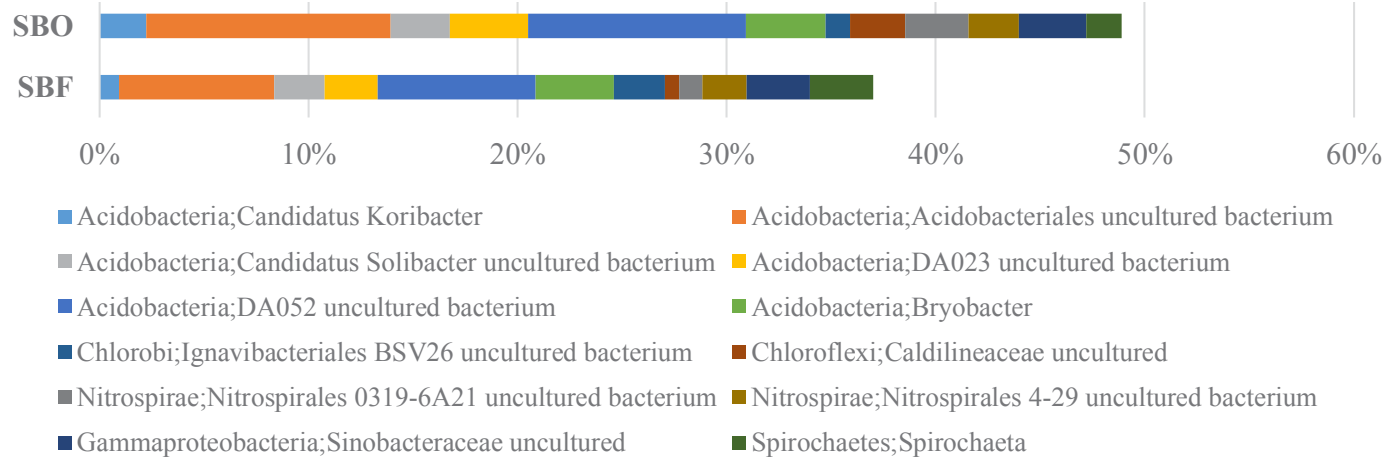

Figure 6. Comparison of the overall distribution of the selected 12 dominant genera (more than $5 \%$ of total sequences) from 50 predominant genera within sites SBF and/or SBO 
16S rRNA gene-based phylogeny showing representatives of all bacterial phyla from tropical low land secondary forest (Figure 7) and oil palm plantation (Figure 8) soil derived sequences have been obtained. The twenty phyla of bacteria were found in SBF site, while fourteen phyla of bacteria were found in SBO site. More phyla in SBF showed that bacterial diversity in SBF was higher than those in SBO.
Proteobacteria was found as the highest phylum abundance in sediment of forest and oil palm plantation area. Alpha and Beta-proteobacteria were more abundance than others class of Proteobacteria, Gamma and Delta-proteobacteria. The fewest abundance among classes of proteobacteria was Gammaproteobacteria in both the forest and plantation areas.

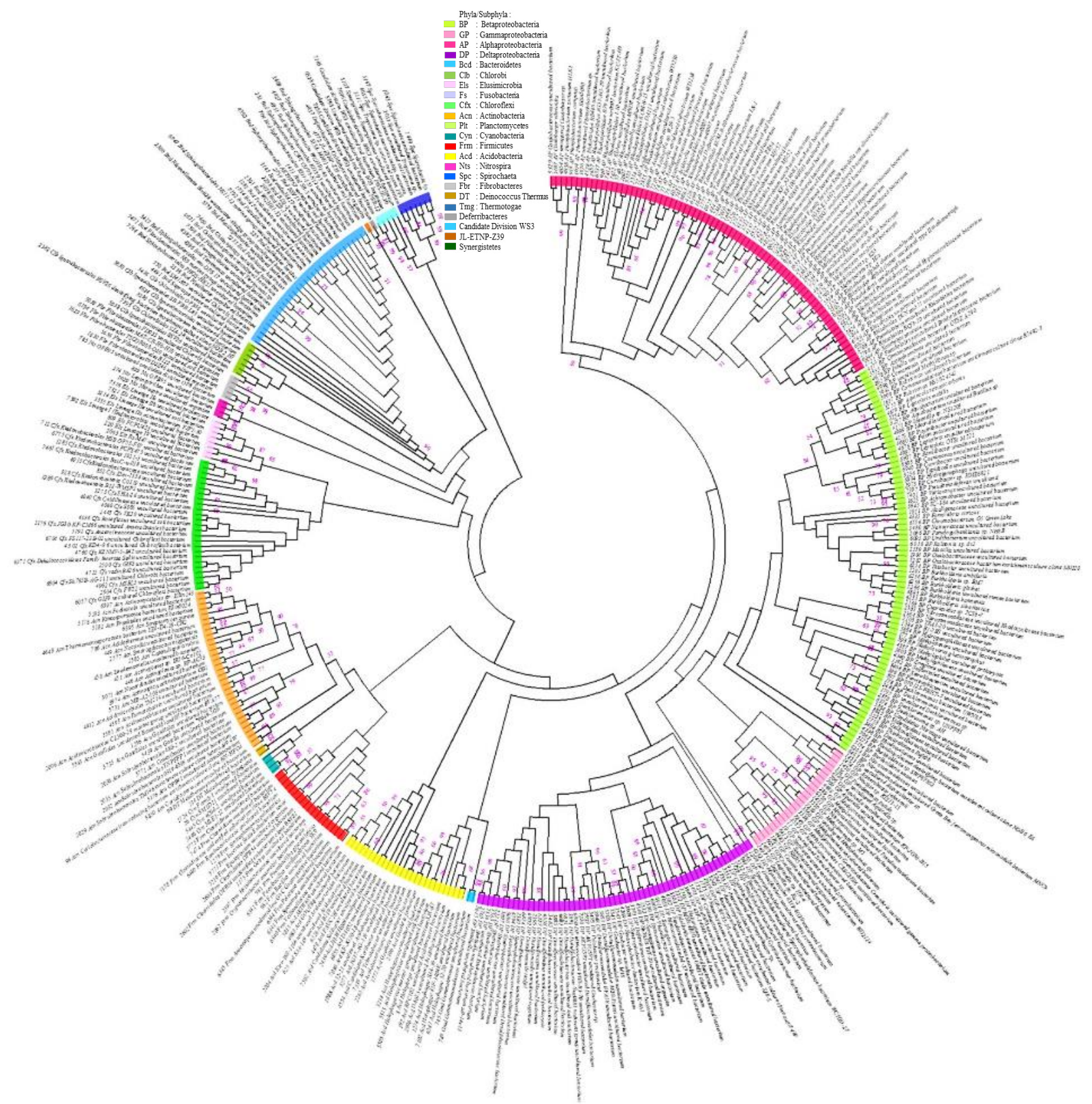

Figure 7. 16S rRNAgene-based phylogeny showing representatives of all bacterial phyla in aquatic sediment from tropical low land secondary forest derived sequences have been obtained. Molecular Phylogenetic analysis by Maximum Likelihood method. The evolutionary history was inferred by using the Maximum Likelihood method based on the Kimura 2-parameter model (Kimura 1980). The tree with the highest log likelihood (-40408.3728) is shown. The percentage of trees in which the associated taxa clustered together is shown next to the branches. Initial tree(s) for the heuristic search were obtained automatically by applying Neighbor-Join and BioNJ algorithms to a matrix of pairwise distances estimated using the Maximum Composite Likelihood (MCL) approach, and then selecting the topology with superior log likelihood value. A discrete Gamma distribution was used to model evolutionary rate differences among sites ( 5 categories $(+G$, parameter $=0.5578)$ ). The rate variation model allowed for some sites to be evolutionarily invariable $([+\mathrm{I}], 12.1163 \%$ sites $)$. The tree is drawn to scale, with branch lengths measured in the number of substitutions per site. The analysis involved 412 nucleotide sequences. All positions with less than $95 \%$ site coverage were eliminated. That is, fewer than $5 \%$ alignment gaps, missing data, and ambiguous bases were allowed at any position. There were a total of 380 positions in the final dataset. Evolutionary analyses were conducted in MEGA6 (Tamura et al. 2013) 
The highest genera in phylogenetic tree (Figure 7 and 8 ) is Burkholderia. Burkholderia is one genus of genera of Betaproteobacteria, similar with in both soil areas. Burkholderia genera were found 8 phylotypes from 42 Burkolderiales in forest freshwater sediment and 4 phylotypes from 19 Burkholderiales in oil palm plantation freshwater sediment. In Burkholderiales (Figure 9), there were seven genera which were found in both areas, such as: Undibacterium, Curvibacter, Variovorax, Caenimonas, Pelomonas, Ideonella, Commamonadaceae uncultured bacterium, and Alcaligenaceae uncultured bacterium.

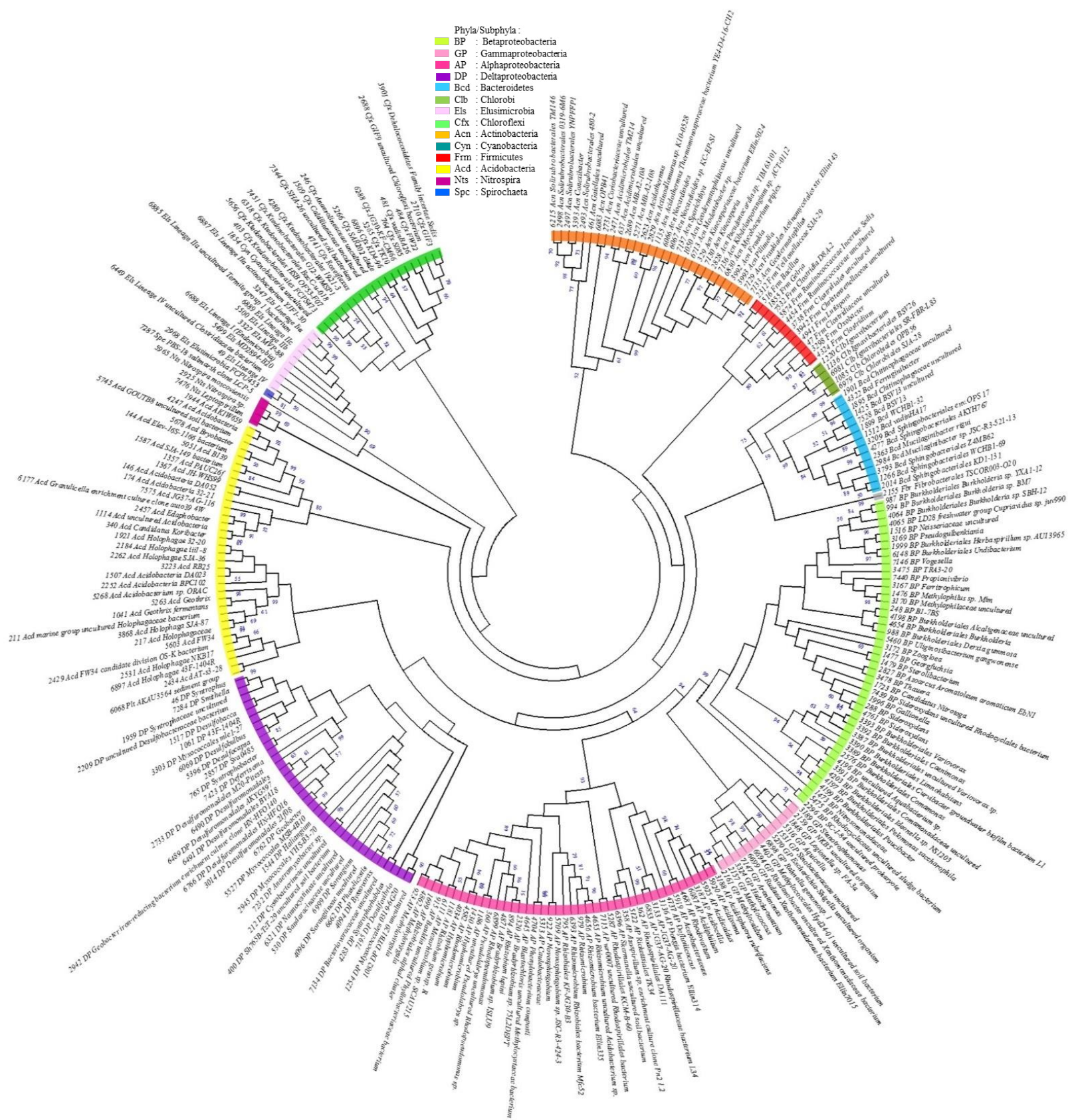

Figure 8. 16S rRNA gene-based phylogeny showing representatives of all bacterial phyla in aquatic sediment from oil palm plantation derived sequences have been obtained. Molecular Phylogenetic analysis by Maximum Likelihood method. The evolutionary history was inferred by using the Maximum Likelihood method based on the General Time Reversible model (Nei and Kumar 2000). The tree with the highest log likelihood (-29292.3205) is shown. The percentage of trees in which the associated taxa clustered together is shown next to the branches. Initial tree(s) for the heuristic search were obtained by applying the Neighbor-Joining method to a matrix of pairwise distances estimated using the Maximum Composite Likelihood (MCL) approach. A discrete Gamma distribution was used to model evolutionary rate differences among sites ( 5 categories $(+G$, parameter $=0.4661)$ ). The rate variation model allowed for some sites to be evolutionarily invariable ([+I], $0.0000 \%$ sites). The tree is drawn to scale, with branch lengths measured in the number of substitutions per site. The analysis involved 266 nucleotide sequences. All positions with less than $95 \%$ site coverage were eliminated. That is, fewer than $5 \%$ alignment gaps, missing data, and ambiguous bases were allowed at any position. There were a total of 427 positions in the final dataset. Evolutionary analyses were conducted in MEGA6 (Tamura et al. 2013) 


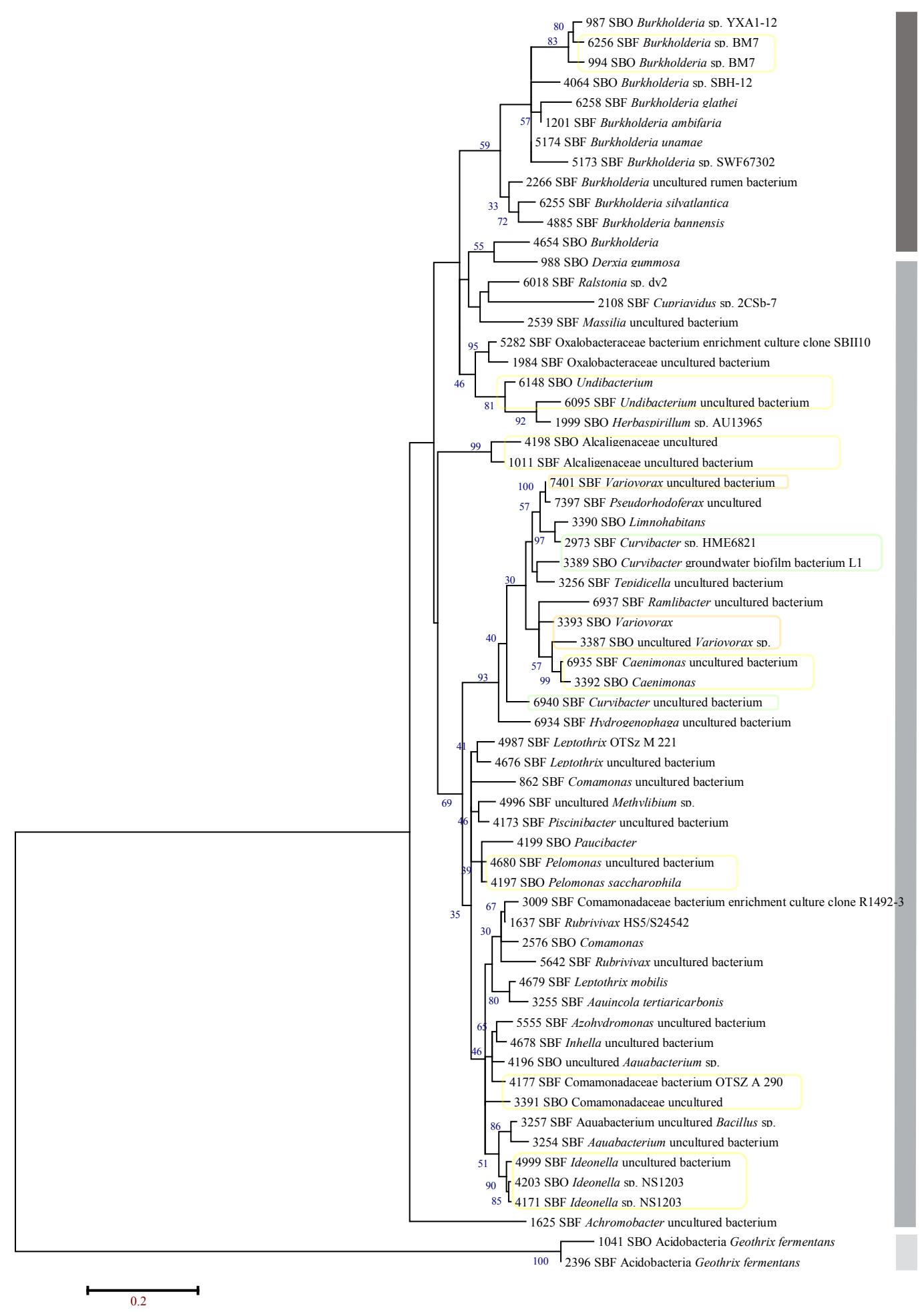

Figure 9. 16S rRNA gene-based phylogeny showing representatives of Burkholderia (Dark grey), other Burkholderiales (Grey) and out group Acd (Acidobacteria) (Light grey) in soil derived sequences have been obtained from SBF and SBO areas. The evolutionary history was inferred by using the Maximum Likelihood method based on the Tamura-Nei model (Tamura and Nei 1993). The tree with the highest log likelihood (-3884.9881) is shown. The percentage of trees in which the associated taxa clustered together is shown next to the branches. Initial tree(s) for the heuristic search were obtained automatically by applying Neighbor-Join and BioNJ algorithms to a matrix of pairwise distances estimated using the Maximum Composite Likelihood (MCL) approach, and then selecting the topology with superior log likelihood value. A discrete Gamma distribution was used to model evolutionary rate differences among sites ( 5 categories $(+G$, parameter $=0.2078)$ ). The rate variation model allowed for some sites to be evolutionarily invariable ([+/], 42.6432\% sites). The tree is drawn to scale, with branch lengths measured in the number of substitutions per site. The analysis involved 63 nucleotide sequences. All positions with less than $95 \%$ site coverage were eliminated. That is, fewer than $5 \%$ alignment gaps, missing data, and ambiguous bases were allowed at any position. There were a total of 372 positions in the final dataset. Evolutionary analyses were conducted in MEGA6 (Tamura et al. 2013) 


\section{Discussions}

Available phosphorus varied significantly between forest and nonforest sites, while soil $\mathrm{pH}$, total carbon, total nitrogen, and $\mathrm{C} / \mathrm{N}$ ratio did not vary significantly across both sediments of the landscape. Direct impacts on aquatic sediment ecosystems from oil palm cultivation include clearing of riparian vegetation for palm planting, sediment run-off from cleared land, and degraded water quality from pollutants (pesticides and fertilizers), mill tailings, and village activities around stream (Sheaves 2014). They can alter the $\mathrm{pH}$, lead to modify the $\mathrm{C} / \mathrm{N}$ ratio and the content of phosphorous in freshwater sediment. The sediment condition was influenced by aquatic column condition. Bacteria were related to Dissolved Organic Carbon (DOC) in the lower aquatic sites, but phosphorus in the upper aquatic. This is likely due to the input of bioavailable carbon in the upper aquatic leading bacteria to be $P$ limited, which changes downstream to carbon limitation as DOC becomes more refractory (Hitchcock and Mitrovic 2015).

Although the carbon (DOC) and the nitrogen were not significant ( $t$ - test) in both sites, but they were used for nutrient of sediment bacteria, so they influenced on bacterial abundance in both area. The phosphorus in both sediment could be the most influential on bacterial abundance, because it was a limiting factor for bacterial growth. Bacterial abundance had been considered by carbon and phosphorus as limiting factors in their habitat of aquatic environment, especially phosphorus for bacterioplankton. Increasing of available phosphorus, total carbon, and total nitrogen in aquatic environment make increasing of bacterial abundance.

Sediment $\mathrm{pH}$ in both area were no significant differences, although soil $\mathrm{pH}$ of SBO sample was higher than those of SBF sample relatively. This condition could be considered by liming on the plantation while receive the run off from oil plantation soil.

Similarly in soil, total carbon and C: $\mathrm{N}$ ratio of freshwater sediment were lower in oil palm soils than in forest area, suggesting that in this case other factors that impact on acid specific bacteria, such as $\mathrm{pH}$, had a strong role might have had on the copiotropic bacteria, like as Proteobacteria (LeeCruz et al. 2013). The plantation run off had been run away with inorganic fertilizer (agricultural lime and phosphorous fertilizer for agricultural management) to downstream sediment. They changed increasing soil $\mathrm{pH}$ even though no significant differences between both areas. Available P in both sites were high - excellent range that reserve of available $P$ in slightly acidic to alkaline soils, possible adverse effects to water quality from erosion of high $P$ soils.

Phosphorus is the second important key element after nitrogen as a mineral nutrient in terms of quantitative primer productivity requirement. Although abundant in water column, its availability is restricted as it occurs mostly in insoluble forms. A substantial number of bacterial species exhibit P solubilization capacity. Available P in site SBF increased nutrient quantity of sediment bacteria at forest area. They impacted to increase on diversities and abundances of soil bacteria in site SBF rather than that in site SBO relatively.

A similar in the bacterial diversity was observed between the two sites, SBF and SBO, suggesting that these two soil systems are not different with diverse soil properties. The data obtained clearly demonstrated that the population of bacteria isolated from sediment of site SBF had slight high diversity, when compared with that from soils of site SBO. The slight differences in the sediment bacterial diversity might be explained by the slight differences in the concentration of TC, TN, and AP. Previous studies have shown that TC, TN, AP, pH, and oxic condition are important regulators of bacterial community composition and activities in the tropical forest and their transformation as oil palm plantation area (Tripathi et al. 2012), (LeeCruz et al. 2013), (Tripathi et al. 2013), (Mishra et al. 2014). In this study, freshwater sediment in both areas were included oxic and micro-oxic condition, because of stream water and shallow creek.

The depth of sampling sediments was about $5-20 \mathrm{~cm}$ under water surfaces of stream river in both areas. The sediments had been microoxic condition, so the range of dissolved oxygen (DO) concentration could be approach by level concentration of DO in shallow stream river at the low land area. The DO level in the low land rivers as interstitial pore water were about $4 \mathrm{mg} / \mathrm{L}$ (Krause et al. 2013). The values can be included in low oxygen concentration in water column.

Availability of C, N, and P make microbiological processes in sediment of forest and oil palm plantation optimally. They acts as binding agent for microbial biofilm and sediment aggregate (Wei et al. 2011). Sediment $\mathrm{pH}$ considered the highest diversity close to neutral $\mathrm{pH}$ values (Tripathi et al. 
2012). Sediment $\mathrm{pH}$ in this study for both areas was acidic ( $\mathrm{pH} 4.5-4.9$ ), so that impacted to increase acidic bacteria composition.

The higher concentrations of inorganic nutrients in freshwater sediment at forest area (Table 1) was on the shifts in benthic microbial communities caused by natural decomposition of organic matter in aquatic sediment at the lowland forest. This study also showed that decreased concentrations of nitrogen total and available phosphorus associated with plantation run off decline benthic bacterial numbers (Figure 2). The toxic compounds may also be present in the effluent, and these may have inhibited bacterial populations. Toxic compounds of pesticides in the effluent could contribute to the reduction in bacterial diversity and species richness at the downstream locations of oil palm plantation area (Lu and Lu 2014). Moreover, rural effluent caused an increase in carbon of the sediment downstream of a rural creek in plantation area. However, decreases in the population size of sediment bacterial communities were also found in the plantation area. This indicated that toxic chemicals from effluents probably played major roles in biotic homogenization of sediment bacterial ecosystem (Lu and Lu 2014).

Five genera dominated in both two sites were included to Acidobacteria phylum. The dominant bacterial phyla from both of two areas were Acidobacteria. Jones et al. (2009) suggested that a strong influence of $\mathrm{pH}$ on microbial communities. Sediment or soil $\mathrm{pH}$ is also a strong predictor of acidobacterial abundance and community composition in the habitat (Jones et al. 2009). Similar with soil composition, in sediment, the relative abundances of Gammaproteobacteria were positively correlated with soil $\mathrm{N}$ and $\mathrm{C}$ content, while acidobacterial relative abundance was correlated with pH factors (Waldrop et al. 2000), (Nemergut et al. 2010). Acidobacteria are also strongly influenced by $\mathrm{pH}$, favoring soils with $\mathrm{pH}$ of 4 (Zavarzin et al. 1991; Wargner et al. 1993). Secondary forest sediment had lower $\mathrm{pH}(4.50 \pm$ $0.56)$ than oil palm plantation soils ( $4.80 \pm 0.10)$, probably promoting Acidobacterial abundance. But, the Acidobacteria in oil palm plantation sediment were more abundance than in forest sediment, in contrast the Proteobacteria in forest sediment were more abundance than in oil palm plantation. There were influent from rural and oil palm plantation to downstream. Bacterial community shift in the oil palm plantation sediment were influenced by the domestic and agrochemical pollutant. So, the acidobacterial abundance increased while bacterial diversity of plantation sediment decreased.
Mechanisms by which water table influences microbial communities are likely to be different in a depth profile, depending on oxygen availability. In the oxic-zones, low water-table sites undergo more pronounced cycles of drying and wetting compared to high-water-table sites. Drying and wetting of peat leads to alternating aerobic and anaerobic physiological responses of the microbes. Thus, drying-wetting process selectively enriches those resilient members of microbial communities that can tolerate these changes both in physical environment and physiological functions. Examples of such successful resilient bacterial taxa are Actinobacteria and Firmicutes that have a very thick peptidoglycan layer to with stand changes in the physical environment and adapt to a broad range of oxygen availability (Mishra et al. 2014).

Proteobacteria might play an important role in water self-purification. The implication is that the $\alpha-, \beta-$, and $\gamma$-Proteobacteria differ in their nutritional requirements, with the $\gamma$-Proteobacteria favored where substrate concentrations are high (Zavarzin et al. 1991; Wargner et al. 1993). Sites of this study had low carbon and nitrogen content (Table 1). Briee et al. (2007) showed that beta- and alpha-Proteobacteria were much more abundant in sediment than in plankton libraries, with the alpha-Proteobacteria nearly absent from water samples. Most delta-Proteobacteria are sulfate reducers; they are abundant and play a cardinal role in anoxic settings, including meromictic and anoxic lakes (Briee et al. 2007). Sequencing the DNA of the recovered clones revealed a high prevalence of the Proteobacteria phylum (57\% of analyzed sequences) (Peixoto et al. 2011). In contrast with Peixoto statement, Gamma-proteobacteria being the fewest abundant group, followed by Deltaproteobacteria, Betaproteobacteria and Alphaproteobacteria, because limited inorganic and organic compound were in aquatic sediment at both sites. Alpha-, Beta-proteobacteria and CytophagaFlavobacteria were influenced by $\mathrm{pH}$, conductivity and temperature as well as by inorganic and organic carbon compounds, whereas phosphorous compounds and nitrate showed specific influence on single bacterial groups. These results can be used to predict future bacterial group shifts, and potential ecosystem functioning, in the landscapes under environmental transformation (Freimann et al. 2014). Beta- and partly Alpha-proteobacteria are often predominant in sediments in lower elevation streams (Kloep et al. 2006; Brablcova et al. 2013).

Betaproteobacteria has been described as a diverse group dominating freshwater systems of different oligotrophic states and are highly 
competitive at the initial state of biofilm development. Betaproteobacteria also have been shown to be involved in the degradation of pollutants, and thus may provide beneficial ecosystem functions within the floodplains. Indeed, precipitation driven pollutant inputs may favor Betaproteobacteria. Biofilm bacterial assemblages in urban rivers have been shown to be dominated by Betaptoteobacteria and Cytophaga-Flavobacteria, which may be linked to their pollution load (Freimann et al. 2014). The alpha-proteobacteria composition taxa was more associated with phenanthrene. The phenanthrene, $16 \mathrm{PAH}$ (polyaromatic hydrocarbon) and specific anthracene $\mathrm{PAH}$, were more associated with the Actinobacteria group. These composition data are important for guiding the choice of potential groups for further bioremediation or for approaches to monitoring each type of pollutant in aquatic sediment ecosystems as similar to mangrove ecosystem (Peixoto et al. 2011). Alphaproteobacteria became more dominant at acidic to intermediate $\mathrm{pH}$ (Griffiths et al. 2011) in soil and aquatic sediment areas. This class had more genera than others because of their capability to survive in acidic soil and degrade herbicide. Similar with oil palm plantation soil, the freshwater sediment contained herbicide for treating unwanted vegetation surrounding areas.

The highest genera in phylogenetic tree (Figure 7 and 8 ) is Burkholderia. Burkholderia is one genus of genera of Betaproteobacteria, similar with in both sediment areas. In study of culturable bacteria, genera of Burkholderia were the most population of bacterial isolates from both areas, forest and oil palm plantation soil freshwater sediment (Wijayanti et al. 2014). Suárez-Moreno et al. (2012) found that the Burkholderia genus comprises 62 validly described species, and their taxonomy has been continuously revised. Two main clusters may be distinguished within the genus Burkholderia. One cluster comprises the B. cepacia complex (BCC), the "pseudomallei" group, and plant pathogens, as well as endosymbiotic species from phytopathogenic fungi. The second cluster contains non-pathogenic Burkholderia species associated with plants and/ or the environment. The non-pathogenic plantassociated species could, therefore, constitute a single clade which contains closely related species (Suárez-Moreno et al. 2012). Burkholderia from this group are mostly associated beneficially with plants, although some species may also survive in sediments and bulk soil. Remarkably, several species from this group can convert atmospheric nitrogen to ammonia via biological nitrogen fixation (BNF). In addition, most of them are catabolically versatile enabling them to degrade recalcitrant compounds, and thus to survive in environments with limited nutrient availability. They tolerate acidity and have a strategy involving both tolerance to abiotic stress factors (Stopnisek et al. 2013). Strains of the genus Burkholderia occupy a wide range of ecological niches and have versatile properties of bioremediation and biocontrol (Coenye and Vandamme 2003). Bacterial sediment of streamline at oil palm plantation area must be more tolerance to ecological stress from pollutants (pesticides and fertilizers), mill tailings, and village activities around stream run off (Sheaves 2014).

There were seven genera which were found in both areas, such as: Undibacterium, Curvibacter, Variovorax, Caenimonas, Pelomonas, Ideonella, Commamonadaceae uncultured bacterium, and Alcaligenaceae uncultured bacterium in Burkholderiales. They play a crucial role in various biogeochemical processes in aquatic. Undibacterium is one genus of 13 genera which included in family Oxalobacteraceae, order Burkholderiales, class Betaproteobacteria. The members of the family are heterotrophic and nonspore-forming gramnegative bacteria. They are mesophilic with the exception of some psychrophilic species. The cells are characteristically Gram-staining-negative, oxidase-positive, rod-shaped, motile by a single polar flagellum and chemo-heterotrophic (Sheu et al. 2014). The predominant habitat of the Undibacterium genus is the water and soil (Kim et al. 2014).

The genus Curvibacter was a Gram-negative, heterotrophic, aerobic, curved rod-formed bacteria. At present, genus Curvibacter comprises three recognized species, the type species Curvibacter gracilis, Curvibacter delicatus (formerly [Aquaspirillum] delicatum), and Curvibacter lanceolatus (formerly [Pseudomonas] lanceolata) (Ding and Yokota 2010). The major characteristics of the genus Curvibacter are the cell shape is slightly curved rods, the flagella arrangement is polar or none, they are aerobic or micro-aerobic, the colony pigmentation is yellow-brown (Ding and Yokota 2010). The genome of a Curvibacter bacterial species that is stably associated with Hydra magnipapillata and the Chlorella (Bosch 2012).

Cells of Variovorax are motile using flagella and occur as single cells or in pairs. Variovorax is Gramnegative and oxidase and catalase positive. The genus is aerobic or facultative anaerobic, and cells 
are generally able to store poly (3-hydroxybutyric acid) as an intracellular carbon source for periods in which extracellular carbon sources are scarcely available (Satola et al. 2013). Caenimonas are Gram-negative, strictly aerobic, non-motile rods bacteria. Catalase- and oxidase-positive. Nitrate is reduced to nitrite and thiosulfate is oxidized to sulfate. No aerobic chemoautotrophic growth with hydrogen as substrate. This genus was isolated from activated sludge performing enhanced biological phosphorus removal in a sequencing batch reactor (Ryu et al. 2008). Pelomonas is betaproteobacteria for anaerobic benzene biodegradation similar with Pseudomonas, while aerobic bacteria for benzene biodegradation include Pseudomonas, Comamonas, Alcaligenes, Acinetobacter and Burkholderia spp. (Liou et al. 2008). Freshwater sediment in forests and their transformation, oil palm plantation, have microaerophilic condition for bacterial growth. They contain several anthrophogenic pollutant. Microaerobic and anaerobic of benzene degrading bacteria play a crucial role for biodegradation process in water table and or water sediment. Ideonella is the chlorate-respiring bacterium and a facultative anaerobe bacteria that can use both oxygen and chlorate as terminal electron acceptors. Chlorate $\left(\mathrm{CIO}^{3-}\right)$ and perchlorate $\left(\mathrm{CIO}^{4-}\right)$ are toxic compounds, mostly of anthropogenic origin, which have been released into soils and waters (Lindqvist et al. 2015). This condition almost occurred in stream of forest and oil palm plantation area as domestic run off.

In aquatic sediment of forest and oil palm plantation area, the special genera of bacteria were Burkholderia. The Burkholderia genus includes species whose ecological properties can differ enormously from each other, and new species colonizing amazingly different habitats are continuously discovered (Paganin et al. 2011). The genus is one of cultivable bacteria and important bacteria which multifunction for human and environment welfare. Acidobacteria and Proteobacteria were the most dominant phyla in oil palm plantation and forest aquatic sediment areas, respectively, because of anthropogenic run off. The genera of alphaproteobacteria and betaproteobacteria dominated in genera phylotype of bacterial 16S rRNA genes phylogenetic revealed both sediment of forest and oil palm plantation. The bacterial community shift in aquatic sediment of forest transformation indicated higher bacterial diversity index, richness index, some of phyla and genera in aquatic sediment from forest than from oil palm plantation. It was caused by plantation management, such as agricultural lime, herbicide, and others handling oil palm plantation.

\section{Acknowledgements}

The authors would like to extend gratitude to Prof. Rolf Daniel and Martin Engelhaupt(rip) for facilitating the molecular work at Genomic Laboratory, Institute of Microbiology and Genetics at Georg-August University Gottingen, Germany. This research was supported by Collaborative Research Center 990 Bogor Agricultural University (B02), and Departement of National Education of the Republic Indonesia (BPPDN 2011 and Hibah Disertasi Doktor from Sriwijaya University).

\section{References}

Ah Tung PG et al. 2009. Effect of $\mathrm{N}$ and $\mathrm{K}$ fertilizers on nutrient leaching and groundwater quality under mature oil palm in Sabah during the monsoon period. Am J Appl Sci 6: 1788-1799.

Bosch TCG. 2012. What hydra has to say about the role and origin of symbiotic interactions? Bio Bull 223: 78-84.

Brablcova L et al. 2013. The phylogenetic structure of microbial biofilms and free-living bacteria in a small stream. Folia Microbiol (Praha) 58: 235-243.

Briee C et al. 2007. Archaeal and bacterial community composition of sediment and plankton from a suboxic freshwater pond. Res Microbiol 158: 213227.

Chao A, Bunge J. 2002. Estimating the number of species in a stochastic abundance model. Biometric 58: 531539.

Coenye T, Vandamme P. 2003. Diversity and significance of Burkholderia Species occupying diverse ecological niches. Environ Microbiol 5(9): 719-729.

Cole JR et al. 2009. The Ribosomal Database Project: Improved alignments and new tools for rRNA analysis. Nucleic Acids Res 37: 141-145.

Comte I et al. 2012. Agricultural Practices in Oil Palm Plantations and Their Impact on Hydrological Changes, Nutrient Fluxes and Water Quality in Indonesia: A Review. In Donald L. Sparks, editor: Advances in Agronomy, Vol. 116 Burlington: Academic Press. pp. 71-124.

Comte I et al. 2015. Watershed-scale assessment of oil palm cultivation impact on water quality and nutrient fluxes: a case study in Sumatra (Indonesia). Environ Sci Pollut Res 22(10): 7676-7695.

Ding L, Yokota A. 2010. Curvibacter fontana sp. Nov., a microaerobic bacteria isolated from well water. $J$ Gen Appl Microbiol 56: 267-271.

Ettenauer JD et al. 2012. Microbes on building materialsEvaluation of DNA extraction protocols as common basis for molecular analysis. Sci Total Environ 439: 44-53. 
Felsenstein J. 1985. Confidence limits on phylogenies: an approach using the bootstrap. Evolution 39: 783791.

Freimann R et al. 2014. Spatio-temporal patterns of major bacterial groups in alpine waters. PLOS ONE 9(11):e113524. doi:10.1371/journal.pone.0113524.

Gibbons SM et al. 2014. Human and environmental impacts on river sediment microbial communities. PLOS ONE 9(5):e97435 doi: 10.1371/journal.pone.0097435.

Griffiths RI et al. 2011. The bacterial biogeography of British soils. Environ Microbiol 13(6): 1642-1654.

Guillaume T et al. 2015. Losses of soil carbon by converting tropical forest to plantations: erosion and decomposition estimated by $\delta 13 \mathrm{C}$. Glob Chang Biol 21: 1-13.

Hitchcock JN, Mitrovic SM. 2015. Highs and lows: The effect of differently sized freshwater inflows on estuarine carbon, nitrogen, phosphorus, bacteria and chlorophyll a dynamics. Est Coast Shelf Sci 156: 71-82.

Jones RT et al. 2009. A comprehensive survey of soil acidobacterial diversity using pyrosequencing and clone library analyses. ISMEJ 3: 442-453.

Kim M et al. 2014. Distinct bacterial communities dominate tropical and temperate zone leaf litter. Microb Ecol 67(4): 837-848.

Kloep $\mathrm{F}$ et al. 2006. Multivariate analysis of microbial communities in the River Elbe (Germany) on different phylogenetic and spatial levels of resolution. FEMS Microbiol Ecol 56: 79-94.

Krause S et al. 2013. Streambed nitrogen cycling beyond the hyporheic zone: Flow controls on horizontal patterns and depth distribution of nitrate and dissolved oxygen in the upwelling groundwater of a lowland river. J Geophys Res Biogeosci 118: 54-67.

Lee-Cruz L et al. 2013. The impact of logging and forest conversion to oil palm on soil bacterial communities in Borneo. Appl Environ Microbiol 79(23):7290-7297.

Lindqvist MH et al. 2015. Chlorate reductase is cotranscribed with cytochrome $c$ and other downstream genes in the gene cluster for chlorate respiration of Ideonella dechloratans. FEMS Microbiol Lett 362(6): 1-5.

Liou JJSC et al. 2008. Field-based and laboratory stable isotope probing surveys of the identities of both aerobic and anaerobic benzene-metabolizing microorganisms in freshwater sediment. Environ Microbiol 10(8): 1964-1977.

Liu $\mathrm{Z}$ et al. 2007. Short pyrosequencing reads suffice for accurate microbial community analysis. Nucleic Acids Res 35:120 -130.

Lu XM, Lu PZ. 2014. Characterization of bacterial communities in sediments receiving various wastewater effluents with high-throughput sequencing analysis. Microb Ecol 67(3): 612-623.

Magurran AE, McGill BJ. 2011. Biological Diversity Frontiers in Measurement and Assessment. New York (US) : Oxford University Press.

Mishra S et al. 2014. Microbial and metabolic profiling reveal strong influence of water table and landuse patterns on classification of degraded tropical peatlands. Biogeoscience 11: 1727-1741.
Nemergut DR et al. 2010. Plot-scale manipulations of organic matter inputs to soils correlate with shifts in microbial community composition in a lowland tropical rain forest. Soil Biol Biochem 42: 2153-2160.

Paganin P et al. 2011. Pathogenicity and biotechnological applications of the genus Burkholderia. Cent Eur J Biol 6(6): 997-1005.

Peixoto $\mathrm{R}$ et al. 2011. Bacterial communities reflect the spatial variation in pollutant levels in Brazilian mangrove sediment. Antonie van Leuwenhoek 99: 341-354.

Quast C et al. 2012. The SILVA ribosomal RNA gene database project: improved data processing and web-based tools. Nucleic Acids Res 11(28): 1-7.

Ryu SH et al. 2008. Caenimonas koreensis gen. nov., sp. nov., isolated from activated sludge. IJSEM 58: 1064-1068

Satola B et al. 2013. Metabolic characteristics of the species Variovorax paradoxus. Appl Microbiol Biotechnol 97:541-560.

Sheaves M. 2014. Impacts include increases in village activities around streams, such as washing and bathing, and overfishing. Roundtable of Sustainable Palm Oil (RSPO) http://betterpalmoildebate. org/22052014.

Sheu SY et al. 2014. Undibacterium squillarum sp. Nov., isolated from a freshwater shrimp culture pond. IJSEM 64: 3459-3466.

Stopnisek N et al. 2013. Genus-wide acid tolerance accounts for the biogeographical distribution of soil Burkholderia populations. Environ Microbiol 16(6): 1503-1512.

Suárez-Moreno ZR et al. 2012. Common features of environmental and potentially beneficial plantassociated Burkholderia. Microb Ecol 63:249-266.

Tan ML et al. 2014. Impacts of land-use and climate variability on hydrological components in the Johor River basin, Malaysia. Hydrological Sci J 60(5): 873889.

Tripathi BM et al. 2012. Tropical soil bacterial communities in Malaysia: $\mathrm{pH}$ dominates in the equatorial tropics too. Microb Ecol 64: 474-484.

Tripathi BM et al. 2013. pH dominates variation in tropical soil archaeal diversity and community structure. FEMS Microbiol Ecol 86: 303-311.

Van Reeuwijk LP. 2000. Procedures for soil analysis. Technical paper/ International Soil Reference and Information Centre (ISSN 0923-3792; no.9).

Waldrop MP et al. 2000. Linking microbial community composition to function in a tropical soil. Soil Biol Biochem 32 : 1837-1846.

Wang $Q$ et al. 2007. Native Bayesian classifier for rapid assignment of rRNA sequences into the new bacterial taxonomy. Appl Environ Microbiol 73: 5261-5267.

Wargner M et al. 1993. Probing activated sludge with oligonucleotides specific for Proteobacteria: inadequacy of culture-dependent methods for describing microbial community structure. Appl Environ Microbiol 59(5):1520-1525.

Wei Y et al. 2011. Relationship between vegetation restoration and soil microbial characteristics in degraded karst regions: A case study. Pedosphere 21(1): 132-138. 
Wijayanti M et al. 2014. Diversity and the composition of fatty acids of lipolytic bacteria isolated from soil and aquatic sediment in a forest and on an oil palm plantation. Makara J Sci 18(3): 71 - 78.

Will C et al. 2010. Horizon-specific bacterial community composition of German grassland soils, as revealed by pyrosequencing-based analysis of 16S rRNA genes. Appl Environ Microbiol 76: 6751-6759.
Zavarzin GA et al. 1991. A correlation of phylogenetic diversity in the Proteobacteria with the influences of ecological forces. Can J Microbiol 37: 1-6. 